\author{
S. Avcioğlu' ${ }^{1}$ T. Mutuk ${ }^{*}$, M. Gürbüz ${ }^{2}$, S. Çevik ${ }^{1}$ \\ ${ }^{1}$ Ondokuz Mayis University, Faculty of Engineering, Metallurgical and Materials \\ Engineering, Samsun, Turkey \\ ${ }^{2}$ Ondokuz Mayis University, Faculty of Engineering, Department of Mechanical Engineering, \\ Samsun, Turkey \\ *tugba.isitan@omu.edu.tr
}

\title{
SINGLE STEP SOLID-STATE SYNTHESIS OF LANTHANUM MOLYBDATE
}

\begin{abstract}
In this study, $\mathrm{La}_{\mathrm{x}} \mathrm{Mo}_{\mathrm{y}} \mathrm{O}_{\mathrm{z}}$ powders were synthesized by a cost-effective solid-state synthesis method. Four different heating cycles were designed to investigate the effects of synthesis temperature and holding time on lanthanum molybdate (LMO) formation, phase assemblies, particle size and morphology. X-Ray Diffraction (XRD) and scanning electron microscopy (SEM) studies were performed to observe crystal structure and particle morphology of synthesized powders. The results showed that nearly ninety percent $\beta-\mathrm{La}_{2} \mathrm{Mo}_{2} \mathrm{O}_{9}(43,3 \mathrm{~nm}$ crystal size) phase was obtained at $1000{ }^{\circ} \mathrm{C}$ for $6 \mathrm{~h}$ holding time. Longer holding times at $1000{ }^{\circ} \mathrm{C}$ favor more oxygen-rich compounds which cause recrystallization of various new crystalline phases. The grain size of the synthesized powder was increased from $0,2 \mu \mathrm{m}$ to $1,5 \mu \mathrm{m}$ with increasing holding time. In summary, it is possible to manufacture LMO powders rich in $\beta-\mathrm{La}_{2} \mathrm{Mo}_{2} \mathrm{O}_{9}$ by one - step solid - state synthesis method. The phase assembles and particle size of LMO powders could also be tailored by optimization of heat treatment cycle.
\end{abstract}

Keywords: heat treatment; lanthanum molybdate; phase assembly; solid state synthesis

\section{INTRODUCTION}

For a decade, lanthanum molybdates has been investigated for ionic conductors because of their high ionic conductivity at about low temperatures $\left(400-800^{\circ} \mathrm{C}\right)$ and it is also a candidate for electrolyte materials to be applied on solid oxide fuel cells SOFCs, oxygen sensors, oxygen pumps and oxygen-permeable membrane catalysts [1]. Therefore, due to its excellent ionic conductivity, $\mathrm{La}_{2} \mathrm{Mo}_{2} \mathrm{O}_{9}$ can be an alternative option to the materials such as yttria-stabilized zirconia (YSZ) which are used for aforesaid application areas [2]. Moreover, low thermal conductivity and good thermal expansion coefficient of $\mathrm{La}_{2} \mathrm{Mo}_{2} \mathrm{O}_{9}$ makes this material a suitable candidate for such applications like thermal barrier coatings (TBCs). There can be found new attractive applications for $\mathrm{La}_{2} \mathrm{Mo}_{2} \mathrm{O}_{9}$ by combining of nanotechnology and thin film characteristics of the powders.

A number of studies have been carried out on different ceramic top layer coating materials for thermal barrier coatings (TBCs) such as $\mathrm{La}_{2} \mathrm{Zr}_{2} \mathrm{O}_{7}, \mathrm{La}_{2} \mathrm{Hf}_{2} \mathrm{O}_{7}, \mathrm{Ce}_{2} \mathrm{Zr}_{2} \mathrm{O}_{7}$, 
$\mathrm{Gd}_{2} \mathrm{Hf}_{2} \mathrm{O}_{7}$ and $\mathrm{La}_{2} \mathrm{Zr}_{2} \mathrm{O}_{7}$ [3-4]. $\mathrm{La}_{2} \mathrm{Mo}_{2} \mathrm{O}_{9}$ which is the other oxide and the subject of present paper is an important research in recent years due to its remarkable properties. Its excellent ionic conductivity at high temperature is better than YSZ [5]. Therefore, $\mathrm{La}_{2} \mathrm{Mo}_{2} \mathrm{O}_{9}$ is a good candidate for TBC material due to its lower thermal conductivity than YSZ [6].

Various research studies have been performed about synthesis of $\mathrm{La}_{2} \mathrm{Mo}_{2} \mathrm{O}_{9}$. Lopez et al. [7] studied that $\mathrm{La}_{2} \mathrm{Mo}_{2} \mathrm{O}_{9}$, has been synthesized using freeze-dried precursor at lower temperature. Then their thermal, electrical properties and XRD analysis compared. In another study, Sellemi et al. [8] investigated that different synthesis method by using polyol processes. Polyol solvent is used in this process and heat treatment is far lower than the commercial synthesis. $\mathrm{La}_{2} \mathrm{Mo}_{2} \mathrm{O}_{9}$ oxide-ion conductor has been synthesized by microwaveassisted combustion method. The microwave sintered $\mathrm{La}_{2} \mathrm{Mo}_{2} \mathrm{O}_{9}$ sample exhibited a conductivity of $0.159 \mathrm{~S} / \mathrm{cm}$ in air at $750{ }^{\circ} \mathrm{C}$ [9].

The red-emitting fine $\mathrm{La}_{2} \mathrm{Mo}_{2} \mathrm{O}_{9}: \mathrm{Eu}^{3+}$ powder phosphors havebeen synthesized with hydrothermal method [10]. Although, there are many powder synthesized studies with dopants, it has structural phase transition at low and high temperature which restrict the practical use of $\mathrm{La}_{2} \mathrm{Mo}_{2} \mathrm{O}_{9}$ powder. Explanation of the phase transitions and phase formations have not been clearly understood. Therefore, it is essential to explain phase structure and their transitions depending on the temperature and time.

The dense bulk samples of $\mathrm{La}_{2} \mathrm{Mo}_{2} \mathrm{O}_{9}$ have usually been produced by solid state reaction. However, in order to increase the efficiency of $\mathrm{La}_{2} \mathrm{Mo}_{2} \mathrm{O}_{9}$ formation, multiple-ball milling steps are used to reduce the grain size of the powders in the conventional manufacturing process. In addition, heat treatment is applied more than once to support phase transformation. That lead to some disadvantages. Such as higher production cost and possible contaminations from balls, mill and sieves used in ball-milling process. So, the preparation of nanocrystalline powders by single stage synthesis make an advantage to provide clean, pure and dense samples at low temperatures with lower manufacturing cost.

In present paper, $\mathrm{La}_{2} \mathrm{Mo}_{2} \mathrm{O}_{9}$ powders were synthesized by cost-effective single-stage solid-state synthesis method. The effects of synthesis temperature and time on $\mathrm{La}_{2} \mathrm{Mo}_{2} \mathrm{O}_{9}$ phase formation were investigated. Starting composition was designed with respect to $\mathrm{La}_{2} \mathrm{O}_{3}$ $\mathrm{MoO}_{3}$ dual phase equilibria. In summary, the synthesis conditions for the formation of $\mathrm{La}_{2} \mathrm{Mo}_{2} \mathrm{O}_{9}$ using solid state reaction were initially optimized and the results were discussed.

\section{EXPERIMENTAL PROCEDURE}

$\mathrm{La}_{\mathrm{x}} \mathrm{Mo}_{\mathrm{y}} \mathrm{O}_{\mathrm{z}}$ powders were synthesized by using solid-state reaction method. The LMO compositions were designed according to $\mathrm{La}_{2} \mathrm{O}_{3}-\mathrm{MoO}_{3}$ dual phase equilibria. Lanthanum (III) oxide $\left(\mathrm{La}_{2} \mathrm{O}_{3}-99.9 \%\right.$, Sigma Aldrich) and molybdenum trioxide $\left(\mathrm{MoO}_{3}, 99.9 \%\right.$, Sigma Aldrich) oxides in a 1:2 molar ratio was milled for $12 \mathrm{~h}$ via conventional ball milling by using zirconia balls. In order to obtain homogeneous submicron particles, 2-propanol $(99.5 \%$, Sigma Aldrich) was used as milling medium. The ball to powder ratio was determined as $1.5: 1$, according to the filling of $10 \mathrm{vol} . \%$ suspension in a closed packed system of spherical 
balls (of approximate $3-5 \mathrm{~mm}$ radius). Then, the mixture slurry was dried at $80^{\circ} \mathrm{C}$ in oven to

remove the alcohol. The dried powders were heat treated at atmospheric conditions in a muffle furnace (Protherm, PLF 120/30) for 3-10 h at 900 and $1000{ }^{\circ} \mathrm{C}$ in alumina crucibles. The phase composition of the synthesized LMO powders was analyzed using the X-ray diffraction method (XRD, Rigaku Smartlab) with $\mathrm{Cu} \mathrm{K \alpha}$ radiation $(\lambda=1.540 \AA)$ from $10^{\circ}$ to $80^{\circ}$ and a scanning speed of $1 \% \mathrm{~min}$ at room temperature. Scanning electron microscopy (SEM, Jeol JSM-7001F) studies were performed to observe the particle morphology of synthesized powders. The average particle size of sintered samples calculated by means of Image-j and Fiji image analyze programs which are freely available in the public domain [1112].

To investigate the effects of the heat treatment cycles on phase assemblage and particle morphology of LMO powders four different heat treatment route were designed. Because of structural phase transition of $\alpha-\mathrm{La}_{2} \mathrm{Mo}_{2} \mathrm{O}_{9}$ (monoclinic) to $\beta-\mathrm{La}_{2} \mathrm{Mo}_{2} \mathrm{O}_{9}$ (cubic) occurs at about $550^{\circ} \mathrm{C}$, all cycles include a soaking step at this temperature. Also starting powder mixture named as Ts 0 were characterized as reference sample. The sample codes and heat treatment steps depending on time and temperature were clearly shown in Fig 1.

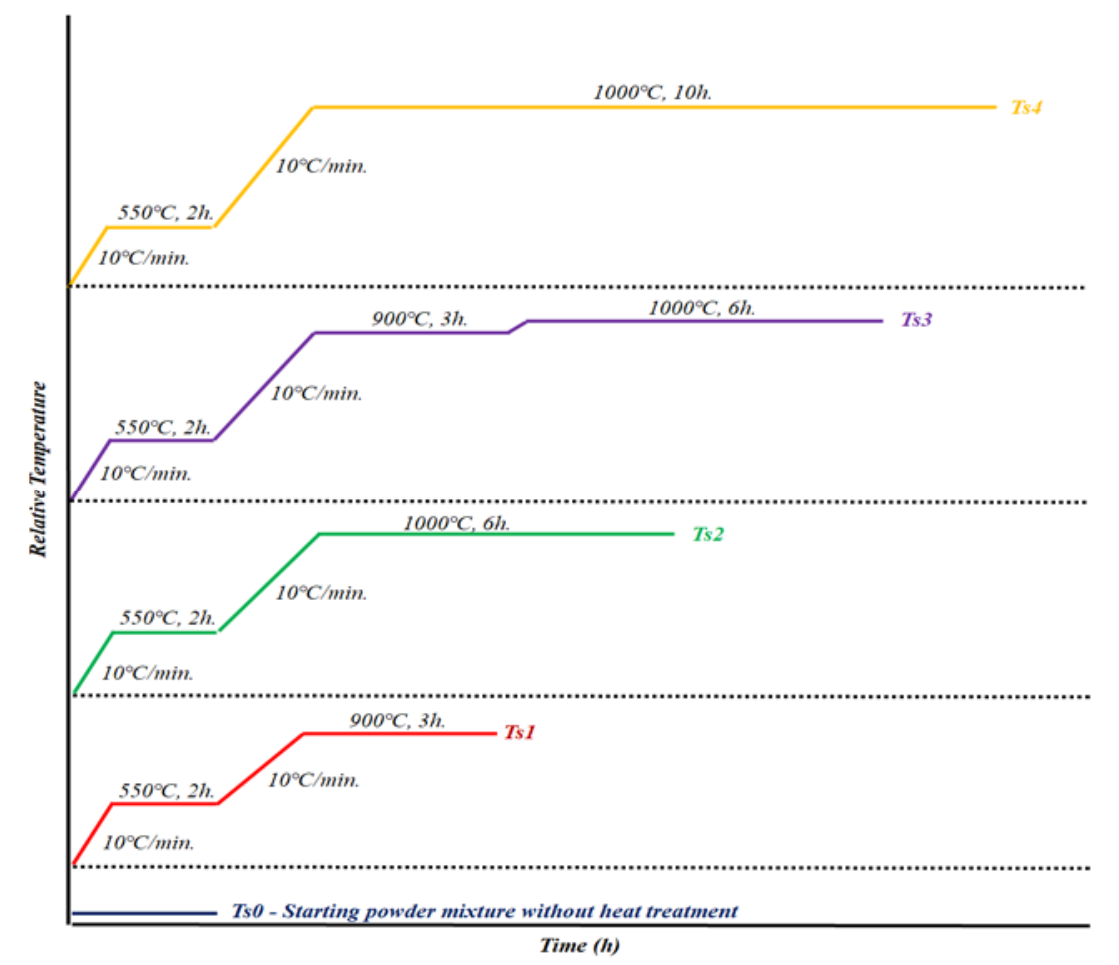

Fig. 1. Heat treatment steps of the samples

\section{RESULT AND DISCUSSION}

The XRD results shows that all samples contain multiple LMO compound. Also, the strong and sharp diffraction peaks suggest that samples are highly crystallized. It is notable that all samples include $\mathrm{La}_{2} \mathrm{Mo}_{2} \mathrm{O}_{9}$ due to the reason that starting powder mixture composition 
lies on $\mathrm{La}_{2} \mathrm{Mo}_{2} \mathrm{O}_{9}$ compound. However, phase assemblage of the samples differs according to the heating cycle. Fig 2 presents the XRD profiles and phase assemblages of the samples calculated by using Match! software (version 3.6). To calculate the phase assemblies of the samples automated rietveld refinement were applied on XRD analysis results by using default settings of the software. It's found that, the samples contain four different LMO compound which are $\mathrm{La}_{2} \mathrm{Mo}_{2} \mathrm{O}_{9}, \mathrm{La}_{6} \mathrm{Mo}_{8} \mathrm{O}_{33}, \mathrm{La}_{2} \mathrm{MoO}_{6}$ and $\mathrm{La}_{2} \mathrm{Mo}_{3} \mathrm{O}_{12}$ with the cod numbers 96-1533393, 96-153-2742, 96-153-9107, 96-201-7004 respectively. From the XRD result of Ts1 sample three different LMO compound produced from first heating cycle. Most dominant crystalline phase of this sample (Ts1) is the oxygen rich one, $\mathrm{La}_{2} \mathrm{Mo}_{3} \mathrm{O}_{12}$ with 67.5 wt.\%. $\mathrm{La}_{2} \mathrm{Mo}_{2} \mathrm{O}_{9}$ phase follows it with $25 \mathrm{wt} . \%$. Also, Ts1 sample includes another crystalline phase which is $\mathrm{La}_{6} \mathrm{Mo}_{8} \mathrm{O}_{33}$ (6.9 wt.\%). $\mathrm{La}_{2} \mathrm{Mo}_{2} \mathrm{O}_{9}$ content dramatically increased (25 to $89 \%$ wt.) when the heat treatment temperature and soaking time were raised $\mathbf{T s} 1\left(900^{\circ} \mathrm{C}, 3 \mathrm{~h}\right.$ holding time) to Ts2 $\left(1000^{\circ} \mathrm{C}\right.$, $6 \mathrm{~h}$ holding time). $\mathrm{La}_{6} \mathrm{Mo}_{8} \mathrm{O}_{33}$ phase was disappeared. Ts3 samples heat treatment cycle includes an additional soaking step at $900^{\circ} \mathrm{C}$ for $3 \mathrm{~h}$. When this cycle applied an additional LMO phase formed $\left(\mathrm{La}_{2} \mathrm{MoO}_{6}\right)$.

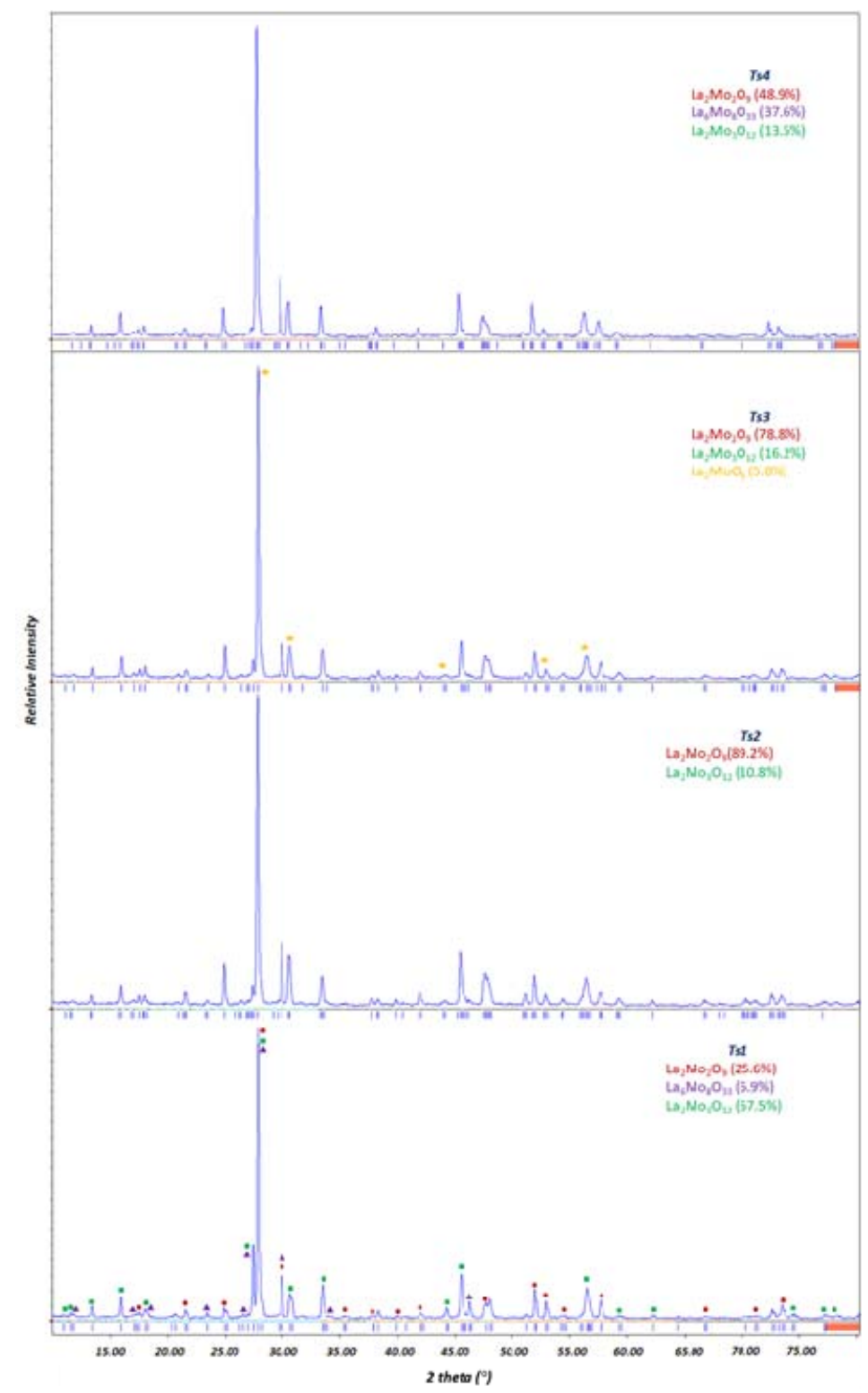

Fig. 2. X-ray powder diffraction patterns of LMO powders 
All identified compounds of lanthanum molybdates positions in the $\mathrm{La}-\mathrm{Mo}-\mathrm{O}$ system are shown at Fig 3. It can be seen that $\mathrm{La}_{2} \mathrm{Mo}_{2} \mathrm{O}_{9}, \mathrm{La}_{6} \mathrm{Mo}_{8} \mathrm{O}_{33}, \mathrm{La}_{2} \mathrm{Mo}_{3} \mathrm{O}_{12}$ phases positions in the phase diagram are very close to each other. On the other hand, fourth compound $\left(\mathrm{La}_{2} \mathrm{MoO}_{6}\right)$ relatively close to the $\mathrm{L}_{2} \mathrm{O}_{3}$ side. The formation of $\mathrm{La}_{2} \mathrm{MoO}_{6}$ phase at Ts3 sample might occur due to the volatilization of molybdenum source compounds. Considering that heat treatment is carried out in a muffle furnace under atmospheric conditions losing some volatile oxides and little composition shift can be acceptable. From the results, the best (nearly 90\%) $\mathrm{La}_{2} \mathrm{Mo}_{2} \mathrm{O}_{9}$ phase formation was performed for Ts 2 .

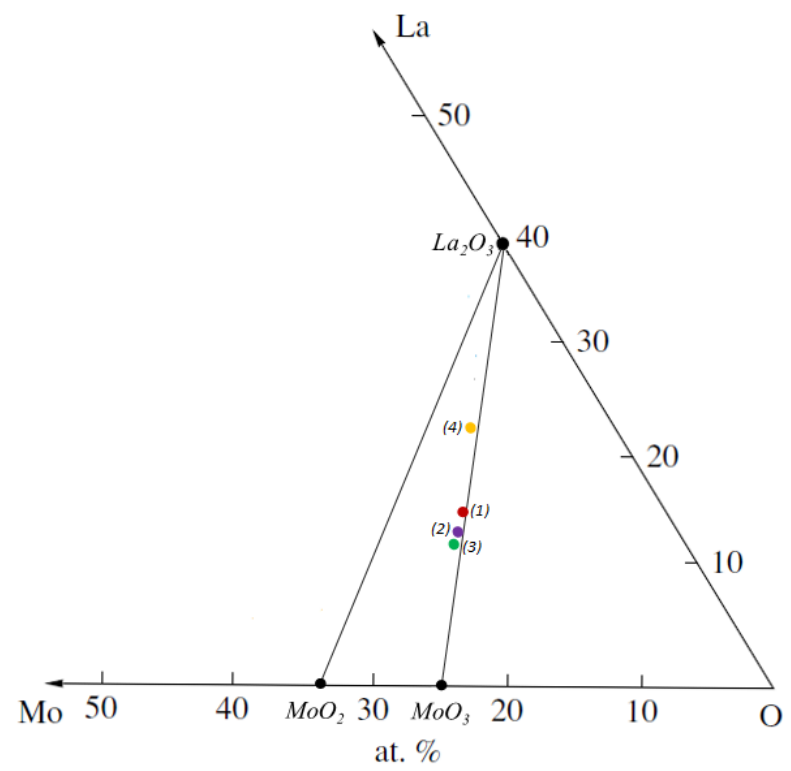

Fig. 3. Identified compounds in the La-Mo-O system: Red-(1) La2Mo2O9, Purple-(2) La6Mo8O33, Green-(3) La2Mo3O12, Yellow-(4) La2MoO6

Paul Scherrer derived a well-known equation for relating the crystallite size to the peak width, which is called the Scherrer formula Eqn (1). This equation is a widely used to determine the crystallite size of polycrystalline samples [13].

where $t$ is the averaged size of crystallites; 0.9 is the Scherrer constant; $\lambda$ is the wavelength of $\mathrm{X}$-ray; and B is the "full-width at half maxima" (FWHM) (in radians 2 $\theta$ ) located at $2 \theta$.

The average crystal size of the LMO samples calculated by using from Eq.(1). Fig 4 shows that by increasing heat treatment temperature and holding time (Ts1 to Ts3) the average crystal size of LMO powders increases $40.94 \mathrm{~nm}$ to $66.7 \mathrm{~nm}$. This result confirm the previous studies which have greater than $30 \mathrm{~nm} \mathrm{La}_{2} \mathrm{Mo}_{2} \mathrm{O}_{9}$ crystal size [14]. There are lots of advantages to obtain the powders in the nanocrystalline size: they ensure faster densification kinetics, lower heat treatment temperatures, better mechanical properties and enhancement of electrical properties [15]. However, the average crystal size of Ts4 sample lower than Ts3. This outcome can be explained by recrystallisation of $\mathrm{La}_{6} \mathrm{Mo}_{8} \mathrm{O}_{33}$ phase. According to the XRD results, the amount of $\mathrm{La}_{2} \mathrm{Mo}_{2} \mathrm{O}_{9}$ phase was reduced by increasing the holding time from Ts3 $\left(1000^{\circ} \mathrm{C}, 6\right.$ hours) to Ts4 $\left(1000^{\circ} \mathrm{C}, 10\right.$ hours $)$, and new $\mathrm{La}_{6} \mathrm{Mo}_{8} \mathrm{O}_{33}$ crystals were formed.

The XRD and Scherer results show that, calcination temperature and time have critical role for phase formation, crystallization and sintering behavior. These properties are directly 
related with diffusion phenomena. Eqn (2) and Eqn (3) give the effect of the time and temperature on the powder properties [16,17]. As given the Scherer calculations, the crystallite size of the LMO samples are increases with increasing temperature and time. With increasing temperature and time enhance the easy atomic movement between the particles which causes to develop the crystal size.

$$
\left.\mathrm{D}=\mathrm{D}_{0} \exp \frac{-Q}{\overline{R T}}\right)
$$

where $\mathrm{D}$ is the diffusion coefficient, $\mathrm{D}_{0}$ is the constant, $\mathrm{Q}$ is the activation energy, $\mathrm{R}$ is the universal energy, $\mathrm{R}$ is the universal gas constant and $\mathrm{T}$ is the temperature.

$$
\mathrm{r}=2.4 \sqrt{D t s}
$$

In this equation, $\mathrm{D}$ is the diffusion coefficient radial distance, and $t_{\mathrm{s}}$ is the calcination time.

The SEM images and the particle size distribution graphs of the synthesized powder are given in Fig 5. All powders have equiaxed and irregular shaped particles. The particle size of LMO powders increases and the particle size distribution become widen by increasing heat treatment temperature and holding time. Its observed that the average particle size of the powder increased from $0.2 \mu \mathrm{m}$ to $1,5 \mu \mathrm{m}$ by changing the heating cycle from Ts1 to Ts4. In general, the phase transition occurs nearly $600{ }^{\circ} \mathrm{C}$ for LMO. Therefore, many studies concentrated on to stabilize crystal structure, electrochemical properties and particle morphology using rare-earth additives. In these studies, oxygen diffusion has a critical role for both transformations of phases and non-stoichiometric phases. The oxygen diffusion is hard due to the difficult oxygen exchange process at the surface. The oxygen diffusion coefficients have been used to evaluate oxygen transport properties for ionic conductive ceramics. Also, the oxygen surface exchange coefficient gives detail about the surface exchange kinetics. Because of these considerations, the phase transformation, morphology and non-stoichiometric phases have been obtained difficult oxygen diffusion which depends the self-diffusion coefficient by a geometric correlation factor. This factor was reported as 0.66 and 0.653 for cubic $\alpha-\mathrm{La}_{2} \mathrm{Mo}_{2} \mathrm{O}_{9}$ and monoclinic $\beta-\mathrm{La}_{2} \mathrm{Mo}_{2} \mathrm{O}_{9}[18]$.

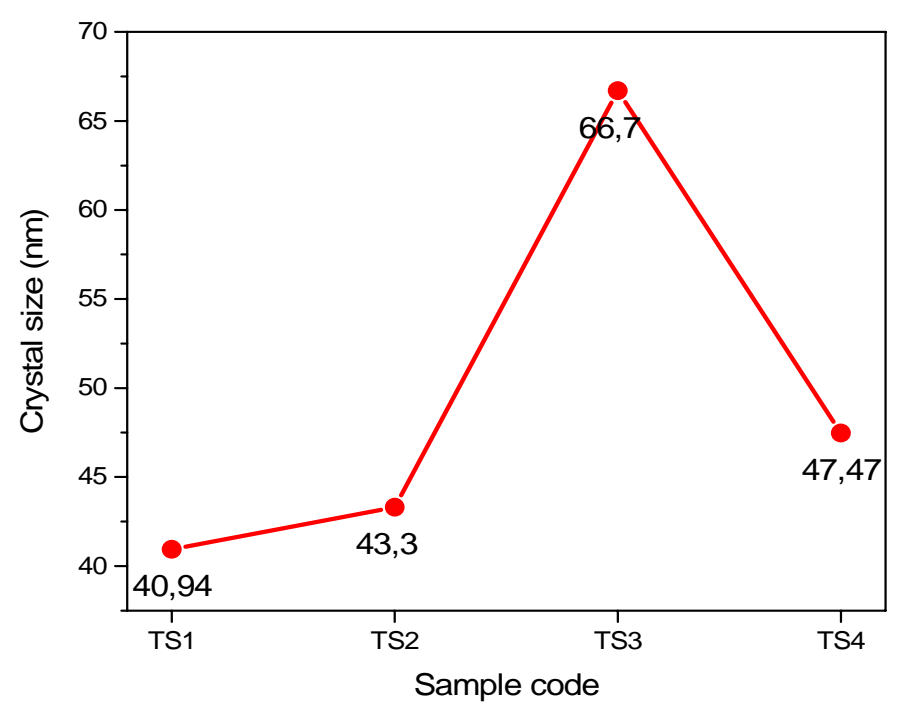

Fig. 4. Average crystal size of La2Mo2O9 for various firing steps 

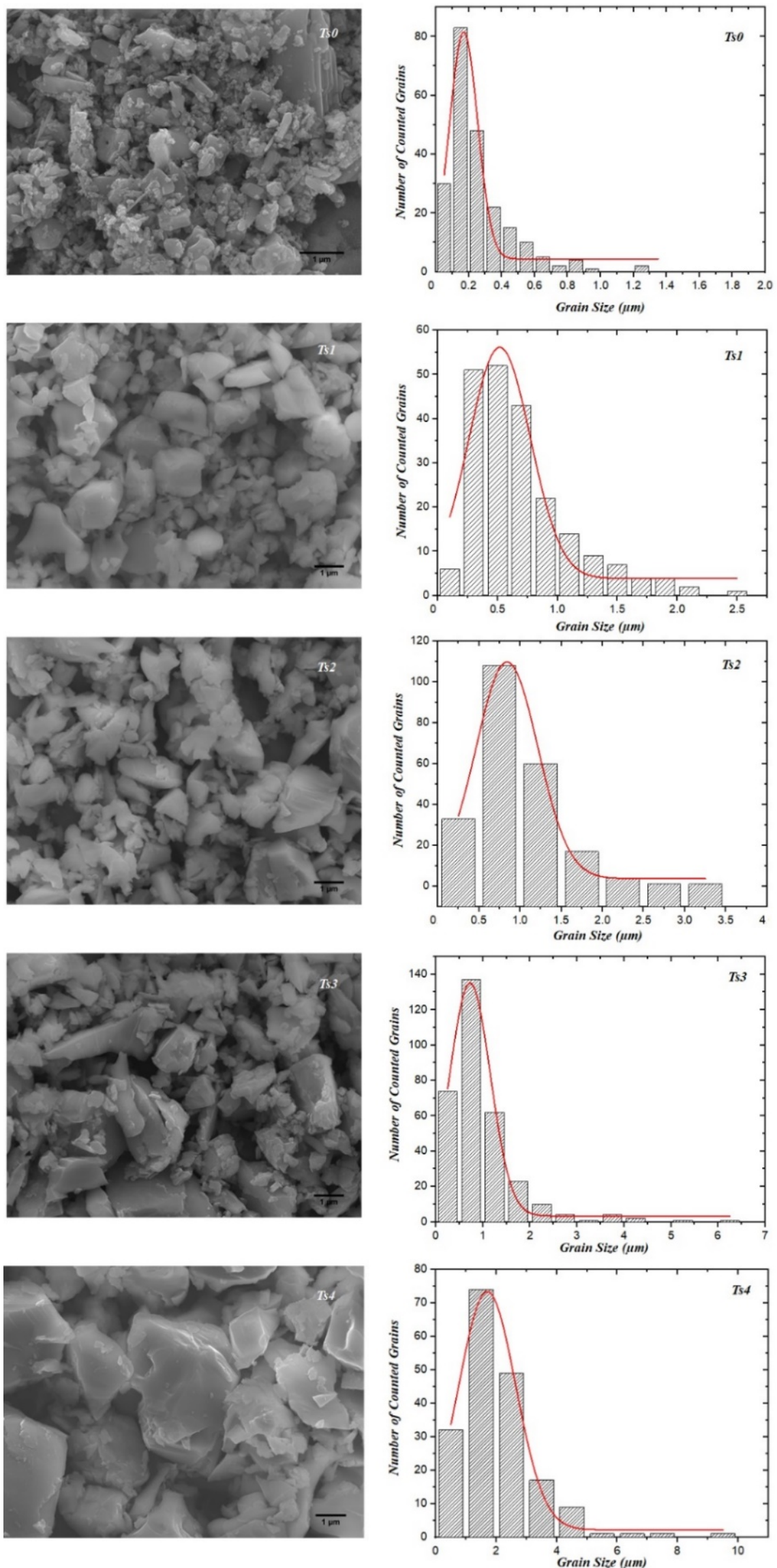

Fig. 5. SEM images of the LMO powders and their particle size distribution results obtained by image 
The EDX and EDX-mapping of TS2 coded LMO powder analyses are given in Fig 6. It is clearly shown that La, Mo and O peaks comes from the LMO powder. Also, mapping signals confirm the $\mathrm{O}$, Mo and La elements in red, blue and green distribution, respectively.

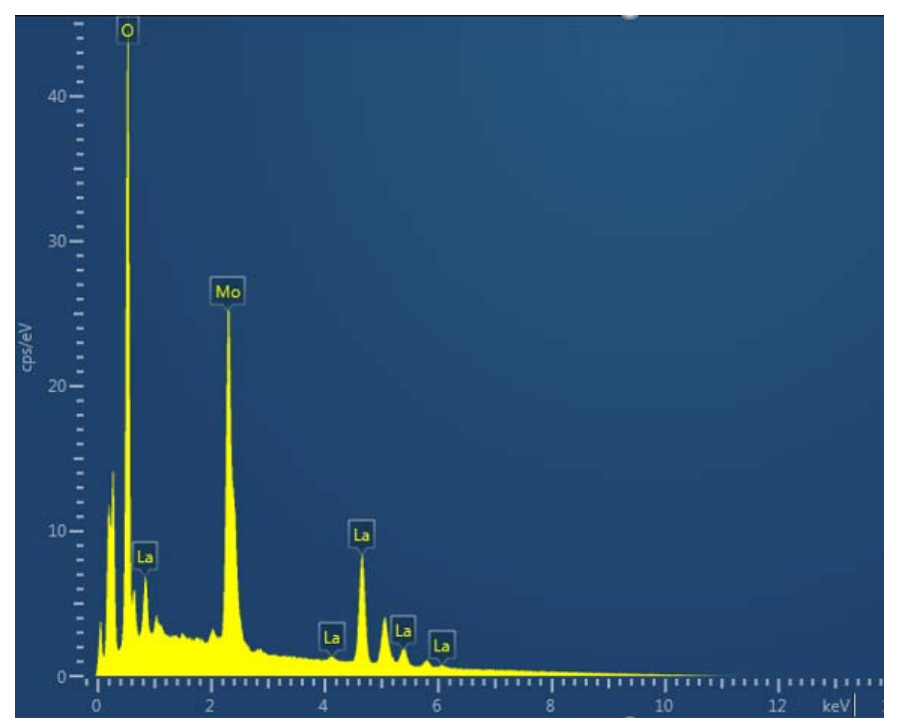

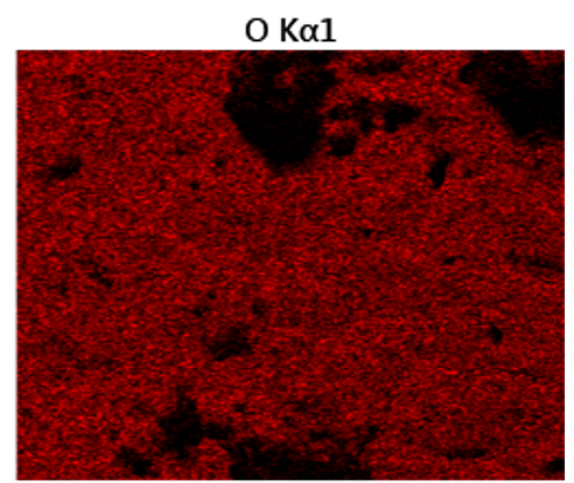

$\longdiv { 2 5 \mu \mathrm { m } }$
Mo L $\alpha 1$

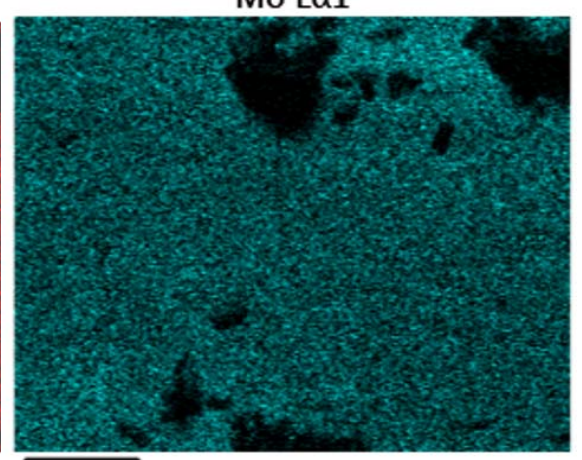

$\longdiv { 2 5 \mu \mathrm { m } }$
La La1

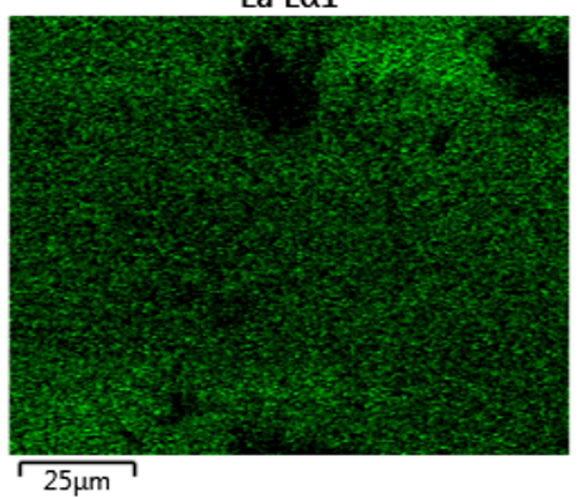

Fig. 6. EDX and EDX-mapping analyses of TS2 coded LMO powder

\section{CONCLUSIONS}

The results of this study can be summarized as:

- $\mathrm{La}_{\mathrm{x}} \mathrm{Mo}_{\mathrm{y}} \mathrm{O}_{\mathrm{z}}$ powders were successfully fabricated by using cost efficient single stage solid state synthesis technique.

- Four different LMO phase $\left(\mathrm{La}_{2} \mathrm{Mo}_{2} \mathrm{O}_{9}, \mathrm{La}_{6} \mathrm{Mo}_{8} \mathrm{O}_{33}, \mathrm{La}_{2} \mathrm{Mo}_{3} \mathrm{O}_{12}, \mathrm{La}_{2} \mathrm{MoO}_{6}\right)$ produced.

- Nearly $90 \% \mathrm{La}_{2} \mathrm{Mo}_{2} \mathrm{O}_{9}$ phase formation was observed by using 1000 heat treatment temperature with $6 \mathrm{~h}$ holding time (Ts2 conditions).

- The LMO powders having average nano crystal sizes were obtained and they tended to increase by increasing heat treatment temperature and holding time changing from 40.94 $\mathrm{nm}$ to $66.7 \mathrm{~nm}$.

- It is possible to tailor phase assembles and particle size of LMO powders by controlling heating cycle.

- Longer holding time on atmospheric conditions favors the oxygen rich LMO compounds. 


\section{REFERENCES}

1. Liu X, Fan X, Shi J. (2011) Anomaly diffuse and dielectric relaxation in strontium doped lanthanum molybdate. Mater. Res. Bull, 4: 2502-2505.

2. Liu J, Chater RJ, Morris RJH, SJ Skinner. (2011) Oxygen surface exchange and diffusion studies of $\mathrm{La}_{2} \mathrm{Mo}_{2} \mathrm{O}_{9}$ in different exchange atmospheres, Solid State Ion., 189: 39-44.

3. Li N, Xiao HY, et al. (2007) First-principles study of electronic properties of $\mathrm{La}_{2} \mathrm{Hf}_{2} \mathrm{O}_{7}$ and $\mathrm{Gd}_{2} \mathrm{Hf}_{2} \mathrm{O}_{7}$, J. Appl. Phys., 102.

4. Jang BK, Kım S, et al. (2011) Influence of $\mathrm{La}_{2} \mathrm{O}_{3}$ addition on thermophysical properties of $\mathrm{ZrO}_{2}-$ $4 \mathrm{~mol} \% \mathrm{Y}_{2} \mathrm{O}_{3}$ ceramics fabricated by spark plasma sintering, J. Ceram. Soc. Jpn., 119, 929-932.

5. Winter MR, Clarke DR. (2007) Oxide Materials with Low Thermal Conductivity, J. Am. Ceram. Soc. 90, 533-540.

6. Ok KM, Ohishi Y, et al. (2017) Effect of Ba concentration on phase stability and mechanical andthermal properties of $\mathrm{La}_{2} \mathrm{Mo}_{2} \mathrm{O}_{9}$, J. Eur. Ceram. Soc., 37, 281-288.

7. Marrero-Lopez D, Ruiz-Morales JC, Nunez P. Abrantes JCC, Frade JR. (2004) Synthesis and characterization of $\mathrm{La}_{2} \mathrm{Mo}_{2} \mathrm{O}_{9}$ obtained from freeze-dried precursors, J. Solid State Chem., 177, 2378-2386.

8. Sellemi H, Coste $\mathrm{S}$, et al. (2013) Synthesis of $\mathrm{La}_{2} \mathrm{Mo}_{2} \mathrm{O}_{9}$ powders with nanodomains using polyol procedure, Ceram. Int., 39, 8853-8859.

9. Saradha T, Muzhumathi S, Subramania A. (2008) Microwave-assisted combustion synthesis of nanocrystalline $\mathrm{La}_{2} \mathrm{Mo}_{2} \mathrm{O}_{9}$ oxide-ion conductor and its characterization, $J$ Solid State Electrochem., 12, 143-148.

10. Shi S, Gong H, Wu J, Ming L, Zhou J. (2012) Synthesis of $\mathrm{Eu}^{3+}$ Activated $\mathrm{La}_{2} \mathrm{Mo}_{2} \mathrm{O}_{9}$ Powder Phosphors by Surfactant Assisted Hydrothermal Approach, J. Am. Ceram. Soc., 95. 3878-3882.

11. Schindelin J, Rueden CT, Hiner MC, Eliceiri KW. (2015) The Image J ecosystem: an open platform for biomedical image analysis, Mol. Reprod. Dev. 82, 518-529.

12. Schindelin J, Arganda-Carreras I, Frise E, et al. (2012) Fiji: an open-source platform for biological-image analysis, Nat. Methods, 9, 676-682.

13. Bulun G. (2010) 3D Transition Metals Ni and Lantanit Gd Substituted $\mathrm{Zn}_{1-\mathrm{x}} \mathrm{O}_{\mathrm{x}}$ Compounds of Structural and Magnetic Properties, Ph.D Thesis, Çukurova University, Ankara.

14. Wang J, Wang Q, Wang X, Li C. (2008) Synthesis and Characterization of Fine Grained High Density $\mathrm{La}_{2} \mathrm{Mo}_{2} \mathrm{O}_{9}$-based Oxide-ion Conductors, J. Mater. Sci. Technol., 24. 761-765.

15 . Fang Z.Z., Wang H. (2010) Sintering of ultrafine and nanosized particles, Woodhead Publishing Series in Met Surf Eng, 434-473.

16. Gürbüz M, Mutuk T. (2018) Effect of process parameters on hardness and microstructure of graphene reinforced titanium composites, J. Comp. Mater., 52: 543-551.

17. Gürbüz M, Şenel MC, Koç E. (2018) The effect of sintering time, temperature, and graphene addition on the hardness and microstructure of aluminum composites J. Comp. Mater., 52: 553563.

18 . Liu J, Chater RJ, Morris RJH., Skinner SJ. (2011) Oxygen surface exchange and diffusion studies of La2Mo2O9 in different exchange atmospheres, Solid State Ion., 189: 39-44. 